Bangladesh J. Bot. 49(3): 473-479, 2020 (September)

\title{
TEMPORAL HETEROGENEITY IN PRIMARY AND SECONDARY METABOLIC PRODUCTS OF MEDICINAL PLANTS OF SITAMATA WILDLIFE SANCTUARY IN RAJASTHAN, INDIA
}

\author{
Arti Soni and Pawan Kumar Kasera* \\ Laboratory of Plant Ecology, Centre of Advanced Study, Department of Botany, \\ Jai Narain Vyas University, Jodhpur 342005, India
}

Keywords: Medicinal plants, Tuber, Phenol, Sitamata wildlife sanctuary

\begin{abstract}
Phyto-chemical investigation in three tuberous medicinal plants, viz., Arisaema tortuosum (Wall.) Schott, Chlorophytum tuberosum (Roxb.) Baker and Curculigo orchioides Gaertn., growing in Sitamata Wildlife Sanctuary of Rajasthan were conducted for both primary and secondary metabolites. Experiment was carried out during June to October to find out monthly variation in accumulation of both primary (total contents of sugars, crude protein and phosphorus) and secondary metabolites (total contents of alkaloids and phenols) in tubers of these three species. In A. tortuosum (Wall.) Schott, crude protein and total alkaloids were found maximum during September, whereas phosphorus and total phenols during July. In C. tuberosum (Roxb.) Baker and C. orchioides Gaertn. maximum values of crude protein, phosphorus and total alkaloids were found during July. It is, therefore, concluded that the maximum production of different metabolites were found to be in the month of July and it is the suitable month for harvesting tubers.
\end{abstract}

\section{Introduction}

The practice of using traditional medicines have a very long history; it is the sum total of the practices based on the theories, beliefs and experiences of different cultures and times, often inexplicable, used in the maintenance of health, as like in the prevention, diagnosis, improvement and treatment of illnesses. Herbal medicine is the use of medicinal plants for prevention and treatment of diseases; it ranges from traditional and popular medicines of every country to the use of standardized and titrated herbal extracts. In every country traditional medicine find foundation in magical or religious beliefs, or popular experience and the WHO is engaged to establish definitive guidelines for methodology of clinical research and the appraisal of effectiveness of traditional medicine (Firenzuoli and Gori 2007).

Plant species produces various metabolic products for their growth and development. Primary metabolites are directly involved in normal growth, development and reproduction. They are of prime importance and essentially required for growth of plants such as sugar, protein, lipids, starch, etc. Many primary metabolites act as precursors of pharmacologically active metabolites (Sagwan et al. 2010). The medicinal actions of plants are unique to particular plant species or groups are consistent with this concept as the combinations of secondary products in a particular plant are often taxonomically distinct (Wink 1999). Studies on plant secondary metabolites have been increasing over the last 50 years. These molecules are known to play a major role in the adaptation of plants to their environment, but also represent an important source of active pharmaceuticals (Bourgaud et al. 2001). The storage organ of plants shows great biological activities. Chemical substances that produce definite physiological actions on human bodies accumulate in storage organs of the plants. The most important of these bioactive compounds are alkaloids, flavanoids and phenolic compounds (Buwa and Staden 2006).

*Author for correspondence: <pkkasera1963@gmail.com>. 
Arisaema tortuosum (Wall.) Schott (Family: Araceae) is a tuberous herb. The paste of the tuber is applied to the wound caused by snake-bite to prevent poisonous effect. Its tubers are useful to treat constipation, indigestion, abdominal pain, dysentery, rheumatism, stomachache, piles and also used as contraceptive, (Azam et al. 2016). In case of abscess in the neck, dried powder of tuber is applied to it. The tubers are used as an anti-oxidant, anti-inflammatory and antiproliferative agent (Nile and Park 2014). The plant grows in large clumps and up to $6.0-7.0 \mathrm{ft}$ in height. It resembles with carnivorous plants, but in fact they attract flies and other insects for pollination, not as food. The fascinating "flower" a pulpit-like hooded spathe enclosing a fleshy, erect spadix usually rises in spring. Flowers and fruits appear during July-August.

Chlorophytum tuberosum (Roxb. ,) Baker (Family Asparagaceae) is found in rainfed areas and have properties such as an aphrodisiac, digestive, rejuvenator and immunomodulator (Chaudhari et al. 2012). Safed musali is used as a galactogogue, having health promoting properties, immuno-enhancing, hepatoprotective, antioxidants activities, etc. (Govindarajan et al. 2005). The tubers are also used in fever and leucorrhoea (Kirtikar and Basu, 1975). The plant is an erect tuberous growing up to a height of $1.5-2.0 \mathrm{ft}$ with sheathing leaf base,. acute to acuminate with entire margin. The roots are tuberous with ellipsoid tubers hanging from them. Flowering and fruiting take place from late June-July and August-September, respectively.

Curculigo orchioides Gaertn., a small herbal plant belongs to the family Hypoxidaceae. Curculigoside, a phenolic glycoside, is the major bioactive compound present has a wide spectrum of pharmacological activities such as an anti-immunostimulant, anti-oxidant, anti-ischemia injury agent, etc. (Wu et al. 2012). In many parts of India, due to its over-exploitation, it is becoming rare in occurrence. In Ayurvedic preparations, roots are considered as an aphrodisiac, appetizer, fattening and useful in treatment of piles, biliousness, fatigue, blood related disorders, etc. In Indian medicine, powdered rhizomes with milk are taken as a restorative tonic and also for the treatment of sexual debility (Khare 2007). It is a perennial herb with thick tuberous rootstock without aerial stem. It grows in the grassy plains and on the hills. Vegetative and flowering take place simultaneously. Flowering and fruiting simultaneously starts from late July and October.

Keeping this in view the present study was initiated with an aim to identify the availability of primary and secondary metabolites in three tuberous medicinally important tuberous plants, i.e. Arisaema tortuosum (Wall.) Schott, Chlorophytum tuberosum (Roxb.) Baker and Curculigo orchioides Gaertn. from Sitamata Wildlife Sanctuary, Rajasthan during different months.

\section{Materials and Methods}

For chemical analyses, tubers of selected plants were collected randomly from natural habitat nearby Sitamata Wildlife Sanctuary, which is located between $74^{\circ} 25^{\prime} \mathrm{E}$ and $24^{\circ} 04^{\prime} \mathrm{N}$ in Paratapgarh district of the Rajasthan State during June-October 2015 to 2017. The tubers were washed with running tap water, oven-dried $48 \mathrm{hrs}$ at $80^{\circ} \mathrm{C}$ and ground for further chemical analyses. The total sugars including soluble and insoluble ones were estimated from oven-dried plant material using the principle of hydroxymethyl furfural reaction with anthrone to produce green colour (Plummer 1971). Tubers were acid digested with $\mathrm{H}_{2} \mathrm{SO}_{4}+\mathrm{H}_{2} \mathrm{O}_{2}$ and crude protein was estimated as per Allen et al. (1976). From the digested solution, nitrogen was estimated by Micro Kjeldahl method as described by Peach and Tracey (1955). Estimation of phosphorus was based on the development of molybdenum blue in sulphuric acid system and measured by spectrophotometer at $700 \mathrm{~nm}$ (Allen et al. 1976). Total alkaloids were estimated by acid-based titrimetric method using methyl red as an indicator and observing a faint yellow end point (Debnath et al. 2015). Total phenols were estimated by Folin-Ciocalteu's method using catechol as standard. This estimation was based on the principle that phenols react with phosphomolybdic 
acid in Folin-Ciocalteu reagent in alkaline medium and produced blue coloured complex, i.e. i.e. molybdenum blue (Bray and Thorpe 1954).

The data collected during the years 2015 to 2017 were subjected to ANOVA (Gomez and Gomez 1984) and mean values are presented in graphical forms.

\section{Results and Discussion}

Biologically active compounds contain a remarkably diverse assay of organic compounds and the carbohydrates are not only the first formed organic compounds in the plants as a result of photosynthesis, but also a major source of energy. The values of total sugars ranged from 38.78 46.99, 40.37 - 52.99 and 30.10 - $48.74 \mathrm{mg} / \mathrm{g} \mathrm{d}$. wt. in A. tortuosum (Wall.) Schott (Fig. 1), C. tuberosum (Roxb.) Baker (Fig. 4) and C. orchioides Gaertn. (Fig.7), respectively. The tubers of $A$. tortuosum were accumulated maximum total sugars during August, whereas in C. orchioides and C. tuberosum during June and September, respectively. Seasonal phytochemical variation in Peganum harmala showed maximum accumulation of total sugars during rainy season (Kedia et al. 2009). Sagar and Kasera (2017) reported maximum total sugars during September in Drimia indica from the Indian Thar desert. According to Singh (2011), the sugar contents in tubers of Costus specious and Pureria tuberosa were 44.51 and $52.26 \mathrm{mg} / \mathrm{g}$ d. wt. during June, respectively, which is almost similar to $C$. orchioides.

Data presented in Fig. 2 show that the crude protein contents in A. tortuosum varied from 26.03 to $83.29 \mathrm{mg} / \mathrm{g}$ d. wt., being maximum during September. The maximum crude protein contents in leaves of Trianthema triquetra during rainy season were reported by Mohammed et al. (2000). In C. tuberosum and C. orchioides, it ranged from 88.50 - 130.15 (Fig. 5) and 70.28 127.55 (Fig. 8) mg/g d. wt, respectively, being maximum during July. Sagar and Kasera (2017) also reported maximum crude protein in leaves of $D$. indica during July. The decline in crude protein was observed in August may be due to the setting of phenological development as the plant transiting from the vegetative to flowering stage.

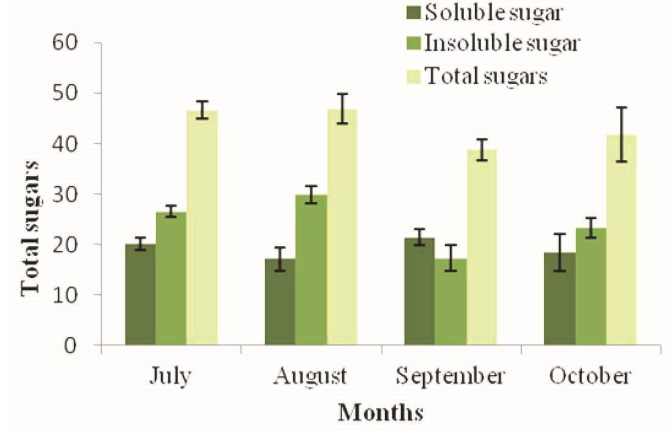

Fig. 1. Sugar contents $(\mathrm{mg} / \mathrm{g})$ in A. tortuosum (Wall.) Schott tubers during different months (Mean values and standard error are presented).

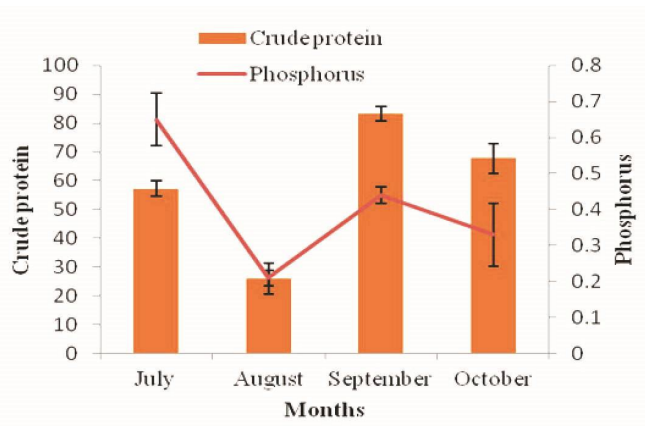

Fig. 2. Crude protein (mg/g) and phosphorus (\%) contents in A. tortuosum (Wall.) Schott tubers during different months (Mean values and standard error are presented).

Phosphorus contents in selected plants were maximum during July when plants were in vegetative phase. Naidu and Swami (1994) and Sagar and Kasera (2017) reported highest amount of phosphorus at the time of new foliage formation in Terminalia arjuna and Dipcadi erythraeum, respectively. In here it ranged from $0.21-0.65$ (Fig. 2), $0.27-0.53$ (Fig. 5) and $0.15-0.56 \%$ (Fig. 8 ) in A. tortuosum, C. tuberosum and C. orchioides, respectively. Similar results were also reported by Sagar (2018) in bulbs of $D$. erythraeum and $D$. indica during vegetative phase. Daiya 
and Kasera (2017) and Gehlot and Kasera (2013) reported maximum phosphorus contents during rainy season in Withania coagulans and Phyllanthus amarus, respectively which is accordance to present results.

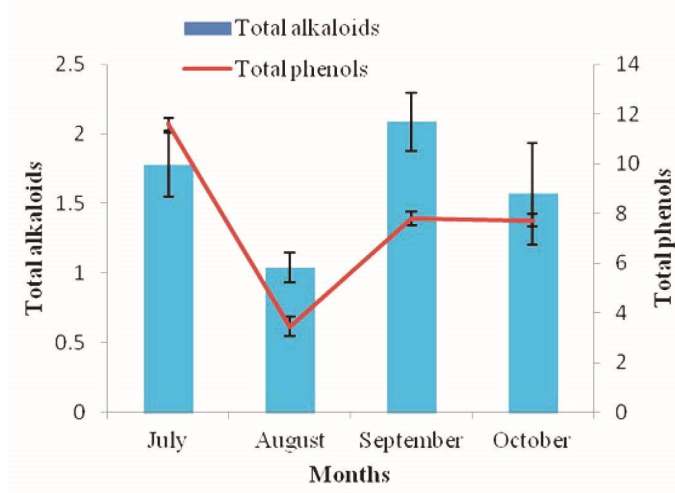

Fig. 3. Total alkaloid (\%) and phenol $(\mathrm{mg} / \mathrm{g})$ contents in A. tortuosum (Wall.) Schott tubers during different months (Mean values and standard error are presented).

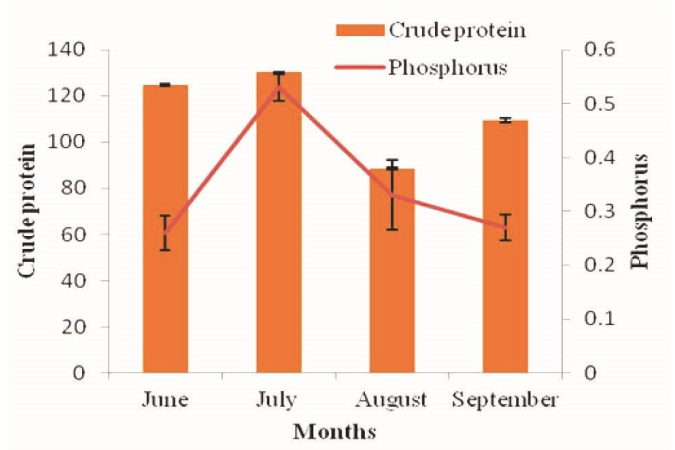

Fig. 5. Crude protein $(\mathrm{mg} / \mathrm{g})$ and phosphorus $(\%)$ contents in C. tuberosum (Roxb.) Baker tubers during different months (Mean values and standard error are presented).

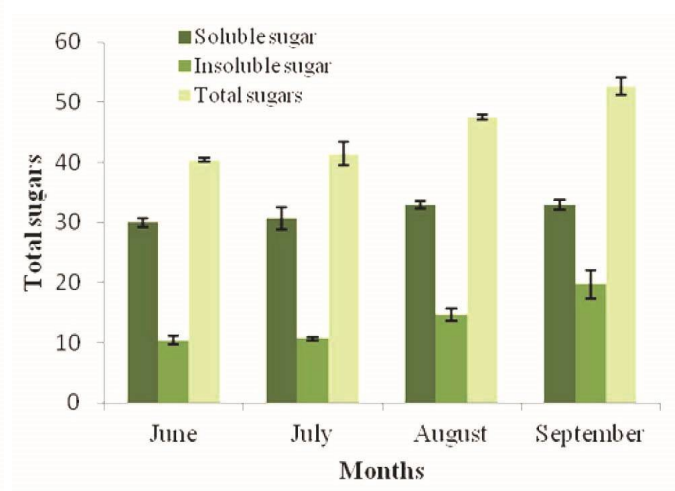

Fig. 4. Sugar contents $(\mathrm{mg} / \mathrm{g})$ in C. tuberosum (Roxb.) Baker tubers during different months (Mean values and standard error are presented).

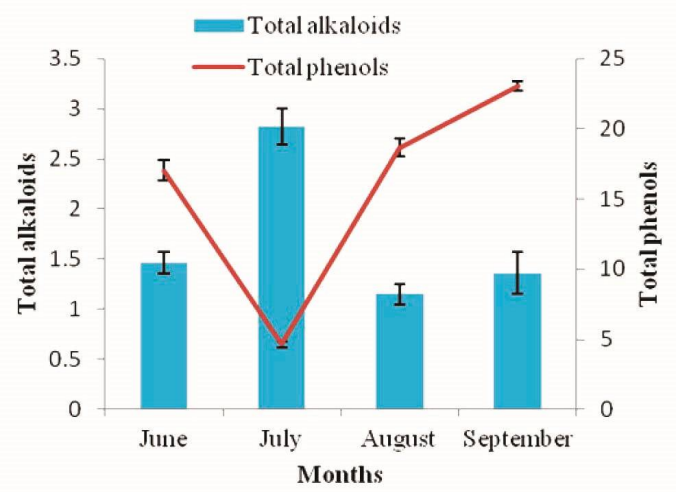

Fig. 6. Total alkaloid (\%) and phenol (mg/g) contents in C. tuberosum (Roxb.) Baker tubers during different months (Mean values and standard error are presented).

Phenolics are groups of secondary metabolites which are synthesized by plant tubers and have indicated to several biological activities such as anti-oxidant, anti-aging, anti-diabetic, antimutagenic, anti-carcinogenic, anti-inflammatory and anti-microbial (Nile and Khobragade 2009). Total phenols in tubers of $A$. tortuosum ranged from 3.45 to $11.60 \mathrm{mg} / \mathrm{g} \mathrm{d}$. wt., being maximum during July (Fig. 3). It is evident from Fig. 9 that the maximum phenolic contents $(22.26 \mathrm{mg} / \mathrm{g}$ d.wt.) in $C$. orchioides were observed during August. Similar results were also reported in Hypericum pruinatum by Ayan et al. (2006). Ncube et al. (2011) and Ahmad et al. (2017) reported maximum total phenols during September in bulbs of Tulbaghia violacea and roots of Solanum incanum, respectively. Similar results were also reported in the present studies with $C$. tuberosum (Fig. 6). There is a well-established positive relationship between the intensity of solar radiation and quantity of phenolics produced by plants (Harbowy and Balentine 1997). In relation to the 
results of the present studies, high phenolic concentrations during rainy season (July - September) could notably be due to the highly fluctuating temperatures.

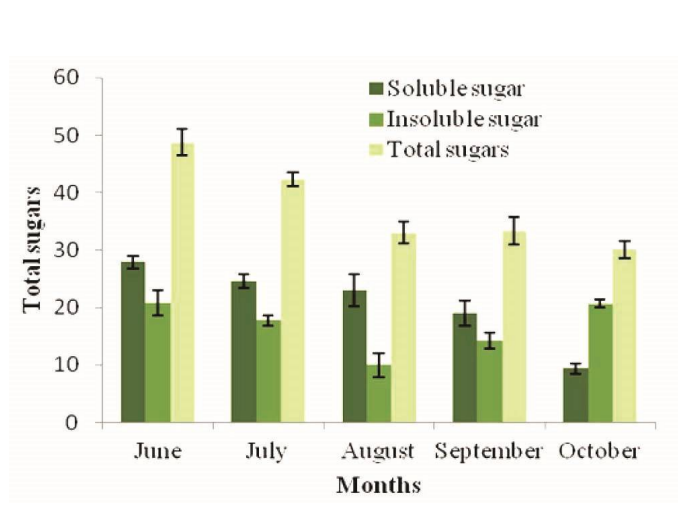

Fig. 7. Sugar contents $(\mathrm{mg} / \mathrm{g})$ in $C$. orchioides Gaertn. tubers during different months (Mean values and standard error are presented).

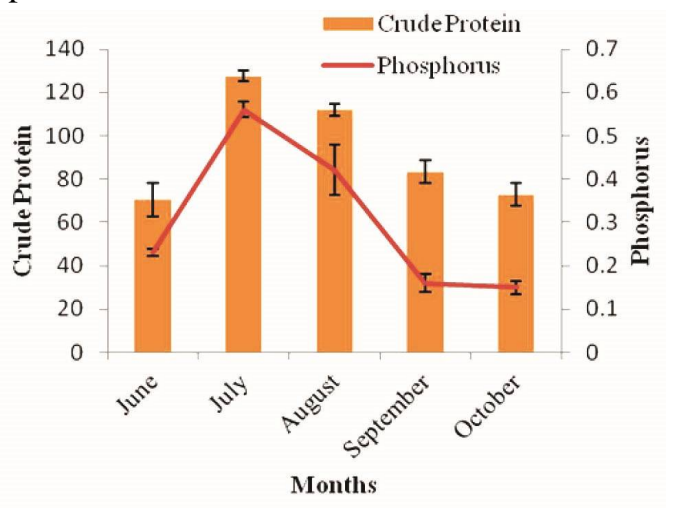

Fig. 8. Crude protein $(\mathrm{mg} / \mathrm{g})$ and phosphorus $(\%)$ contents in C. orchioides Gaertn. tubers during different months (Mean values and standard error are presented).

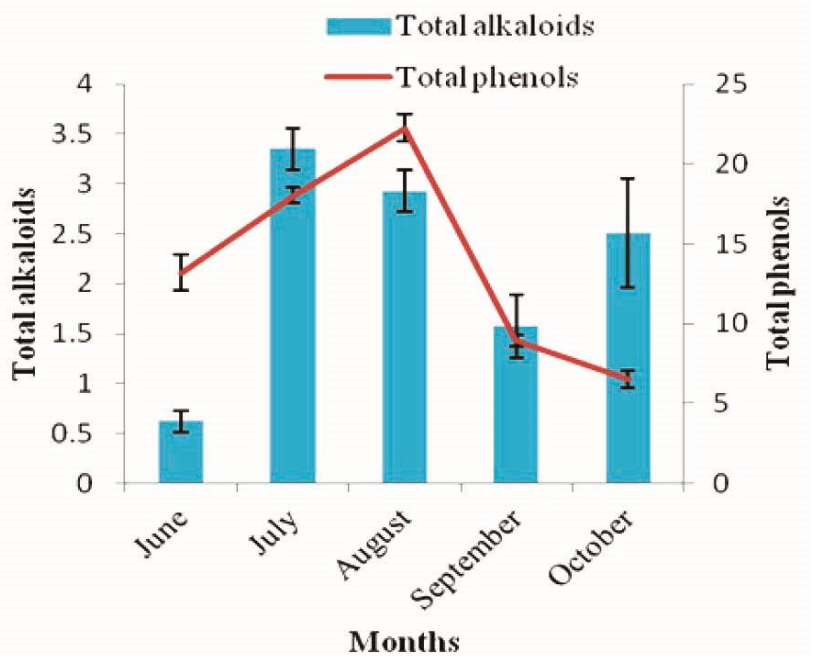

Fig. 9. Total alkaloid (\%) and phenol (mg/g) contents in C. orchioides Gaertn. tubers during different months (Mean values and standard error are presented).

The alkaloids are naturally occurring nitrogen-containing pharmacologically active organic compounds present in plant kingdom and have made major impact on plant medicine because of its vast application. In Ayurveda, it is believed that many of Tikta (bitter) and Katu (pungent) tasted herbs are rich in alkaloids. In tubers of A. tortuosum, higher amount to total alkaloids were found during September (Fig. 3). Kale (2010) observed highest total alkaloids in Datura metel during rainy season. The leaves of $C$. orchioides showed highest total alkaloids during September (Soni and Kasera 2018). C. orchioides (Fig. 6) and C. tuberosum (Fig. 9) exhibit peak concentration of total alkaloids during July and then gradually decreasing trend was observed in later months. In Aconitum elwesii, crude alkaloid content was maximum during pre-flowering seasons (July-August), whereas in roots during November (Sinam and Devi 2011). 
Statistical analyses revealed that sampling month is the only factor contributing for the observed variations in total sugars, crude protein and total phenols $(\mathrm{p}<0.05$ levels $)$ in all these three plants, while phosphorus and total alkaloids varied non-significantly in A. tortuosum. Except phosphorus, data for all parameters were significant in C. tuberosum.

It can be concluded from present study that tubers of all these three species showed maximum phosphorus contents during July. Higher amount of crude protein and total alkaloids were observed during September while in two other species during July. In A. tortuosum, total sugars and phenols were maximum in August and July, respectively while in in C. tuberosum during September. $C$. orchioides exhibited maximum values of total sugars and phenols in June and August, respectively. Tubers of $C$. tuberosum accumulated higher amount of total phenols as compared to other plants, however total alkaloids were maximum in C. orchiodes. The tubers of these plant species could feasibly be harvested during rainy season (July-September) for medicinal use to cure different diseases for improving the sustainability of these medicinal plant resources. Phenolic and alkaloid compound levels appeared to be higher during rainy season, a phenomenon which implies that the periods coincide with the favourable stimuli for the production of these metabolites.

\section{Acknowledgements}

The authors are thankful to Professor \& Head, Department of Botany, Centre of Advanced Study, J. N. Vyas University, Jodhpur for providing necessary facilities. Grateful thanks to the CSIR, New Delhi for the financial assistance in the form of NET-SRF fellowship \{09/098)0126)/2013-EMR-1\} to the first author (AS). Financial support received from the UGC, New Delhi in the form of UGC-(SAP-II)-CAS (No. F. 5-1/2013(SAP-II) dated 03.01.2014) is also gratefully acknowledged. Thanks to the authority of Forest Department of Sitamata Wildlife Sanctuary for kind permission to collect plant materials.

\section{References}

Ahmad I, Hussain M, Ahmad MSA, Sultan MA, Ashraf MY, Iftikhar M, Noreen A and Muneeb A 2017. Spatio-temporal variations in nutritional and medicinal properties of thorn apple (Solanum incanum L.), a rare medicinal plant species of the salt range. Pak. J. Bot. 49: 201-210.

Allen SE, Grimshaw HM, Parkinson JA, Quarmb C and Roberts JD 1976. Chemical analysis. In: Methods in Plant Ecology. Chapman SB (Ed), pp. 536. Blackwell Scientific Publications, USA.

Ayan AK, Clrak C and Yanar O. 2006. Variations in total phenolics during ontogenetic morphogenetic and diurnal cycles in Hypericum species from Turkey. J. Plant Biol. 49: 432-439.

Azam S, Saqib MS, Zar F, Ahmad B, Khan I, Zeb Z and Khan I 2016. Antibacterial, antifungal, phytotoxic, antioxidant and hemagglutination activities of organic fractions of Arisaema tortuosum. Pak. J. Pharm. Sci. 29: 991-997.

Bourgaud F, Gravot A, Milesi S and Gontier E 2001. Production of plant secondary metabolites: A historical perspective. Plant Sci. 161: 839-851.

Bray HG and Thorpe WV 1954. Analysis of phenolic compounds of interest in metabolism. Methods Biochem. Anal. 1: 27-52.

Buwa LV and Staden JV 2006. Antibacterial and antifungal activity of traditional medicinal plants used against venereal diseases in South Africa. J. Ethnopharmacol. 103: 139-142.

Chaudhari SA, Peter J, Galgut JM and Ali SA 2012. Melanin inhibitory and melanin stimulatory effects of extracts of Chlorophytum tuberosum and Chlorophytum borivilianum on isolated fish scale melanophores. Afr. J. Pharm. Pharmacol. 6: 919-923.

Daiya K and Kasera PK 2017. Seasonal phytochemical evaluation of Withania coagulans - An important medicinal plant of the Indian Thar desert. JMAPS 39: 83-87. 
Debnath B, Jashimuddin MD, Patari P, Das M, Maiti D and Manna K 2015. Estimation of alkaloids and phenolics of five edible cucurbitaceous plants and their antibacterial activity. Int. J. Pharm. Pharm. Sci. 7: 223-227.

Firenzuoli F and Gori L 2007. Herbal medicine today: Clinical and research issues. Evid-based Complementary Altern. Med. 4: 37-40.

Gehlot M and Kasera PK 2013. Variability in primary and secondary metabolites during different seasons in Phyllanthus amarus. Ind. J. Plant Physiol. 18: 169-171.

Govindarajan R, Vijayakumar M and Pushpangadan P 2005. Antioxidant approach to disease management and the role of 'Rasayana' herbs of Ayurveda. J. Ethnopharmacol. 99: 165-178.

Gomez KA and Gomez AA 1984. Statistical procedures for agricultural research, (2nd edn.), John Wiley \& Sons, USA, pp. 294.

Harbowy ME and Balentine DADA 1997. Tea chemistry. Crit. Rev. Plant Sci. 16: 415-480.

Kale VS 2010. Variable rates of primary and secondary metabolites during different seasons and physiological stages in Convolvulus, Datura and Withania. Asian J. Exp. Biol. Sci. SPL: 50-53.

Kedia S, Kasera PK and Mohammed S 2009. Ecophysiology of Peganum harmala L. during three seasons and growth stages. Proc. Nat. Acad. Sci. India, Sect B 79: 267-270.

Khare CP 2007. Indian medicinal plants - An illustrated dictionary. Springer, Berlin, p. 185.

Kirtikar KR and Basu BD 1975. Indian Medicinal Plants. In: Liliaceae: Chlorophytum . pp. 2508-2509. LM Basu Publishers, Allahabad, India.

Mohammed S, Kasera PK and Sen DN 2000. Ecophysiology of Trianthema triquetra Rottler ex Willd, a halophyte of Indian desert. Ecoprint 7: 57-62.

Naidu CV and Swami PM 1994. Seasonal variation in N, P and K content of different plant parts in tropical deciduous tree species. Ind. J. Plant Physiol. 37: 224-228.

Ncube B, Finnie JF and Staden JV 2011. Seasonal variation in antimicrobial and phytochemical properties of frequently used medicinal bulbous plants from South Africa. Afr. J. Bot. 77: 387-396.

Nile SH and Khobragade CN 2009. Determination of nutritive value and mineral elements of some important medicinal plants from western part of India. J. Med. Plants 8: 79-88.

Nile SH and Park SW 2014. HPTLC analysis, antioxidant, anti-inflammatory and anti-proliferative activities of Arisaema tortuosum tuber extract. Pharm Biol. 52: 221-227.

Peach K and Tracey MV 1955. Modern methods of plant analysis. Springer, Berlin, pp. 718.

Plummer DT 1971. An introduction to practical biochemistry. Tata McGraw Hill Publishing Co. Ltd, New Delhi, pp. 369.

Sagar A and Kasera PK 2017. Biology, seed morphology, germination and phytochemical analysis of Drimia indica (Roxb.) Jessop from the Indian Thar desert. Int. J. Ecol. Environ. Sci. 43: 239-243.

Sagar A 2018. Vegetation and ecophysiological studies of some aphrodisiac tuberous plants from Indian arid zone. Ph.D. Thesis, JNV University, Jodhpur, India.

Sagwan S, Rao DV and Sharma RA 2010. Biochemical estimation of primary metabolites from Pongamia pinnata (L.): An important biodiesel plant. Int. J. Pharm. Sci. Rev. Res. 5: 146-149.

Sinam YM and Devi GAS 2011. Seasonal variation of bioactive alkaloid content in Aconitum spp. from Manipur India. The Bioscan 6: 439-442.

Singh N 2011. Wild edible plants: A potential source of nutraceuticals. Int. J. Pharm. Sci. Res. 2: 216-225.

Soni A and Kasera PK 2018. Evaluation of secondary metabolites in three tuberous medicinal plants during different months from south-eastern part of Rajasthan. J. Pharmaco. Phytochem. 7: 474-477.

Wink M 1999. Introduction, biochemistry, role and biotechnology of secondary products. In: Biochemistry of secondary product metabolism, Wink M (Ed), pp. 1-16. CRC Press, Boca Raton, USA.

Wu XY, Li JZ, Guo JZ and Hou BY 2012. Ameliorative effects of curculigoside from Curculigo orchioides Gaertn on learning and memory in aged rats. Molecules 17: 10108-10118. 